\title{
Os tempos no Paraguaçu: juventude, mediações culturais e Youtube
}

\author{
Daniela Abreu Matos' \\ https://orcid.org/0000-0002-3859-8488 \\ Jussara Peixoto Maia \\ https://orcid.org/0000-0003-3996-6673 \\ Valéria Maria Vilas-Bôas" \\ http://orcid.org/0000-0001-8335-4979 \\ I - Universidade Federal do Recôncavo da Bahia \\ Cachoeira (BA), Brasil \\ II - Centro Universitário Jorge Amado \\ Salvador (BA), Brasil
}

Resumo: O presente texto analisa as produções audiovisuais da Equipe Iskálifá, coletivo formado por jovens moradores de São Félix-BA, sob a ótica das mediações sociais e mutações culturais, nos termos de Jesus Martin-Barbero. O percurso analítico identifica como a contradição da luta cultural opera em diferentes temporalidades na configuração dos produtos. O objetivo é evidenciar o duplo esforço implicado, de produção de material audiovisual e de sujeitos produtores que revelam movimentos do tempo transpassados por valores, sentidos e práticas hegemônicas, alternativas e oposicionais.

Palavras-chave: juventude; contradição; mediações; temporalidades; Youtube.

Abstract: The times in Paraguaçu: youth, cultural mediations and Youtube - This paper analyzes the audiovisual productions of Equipe Iskálifá, a group formed by young residents of São Félix-BA, from the standpoint of social mediations and cultural mutations, in the terms of Jesus Martin-Barbero. The analytical course identifies how the contradiction of cultural struggle operates in different temporalities in the configuration of products. The objective is to highlight the implied double effort of production of audiovisual material and subjects, and reveal time movements passed through values, meanings and alternative and oppositional hegemonic practices.

Keywords: youth; contradiction; mediations; temporalities; Youtube. 
O olhar analítico aqui exercitado tem como centralidade textos produzidos por jovens, em articulação coletiva, que acionam a marca da periferia ou de espaços periféricos para sua auto-identificação e narram suas experiências vividas nesses lugares ou a partir deles. O acionamento do grupo está atento às reverberações do processo de escrita que, para Rancière, é político "porque seu gesto pertence à constituição estética da comunidade e se presta, acima de tudo, a alegorizar essa constituição" (1995, p. 7) e desorganiza qualquer pretensão de fixidez que os localize dicotomicamente entre textos integrados ou resistentes. A proposta está em diálogo com Bhabha - que ao discutir a experiência moderna de nação ocidental - indica que "precisamos de um outro tempo de escrita que seja capaz de inscrever as interseções ambivalentes e quiasmáticas de tempo e lugar" (BHABHA, 1998, p. 201).

Atentas à dimensão transformadora e resistente dessas falas, e até mesmo para explorar sua potencialidade, e identificar uma possível "temporalidade disjuntiva" (BHABHA, 1998, p. 210) ${ }^{1}$ realizamos um exercício analítico de produções audiovisuais da Equipe Iskálifá, coletivo formado por jovens moradores de São Félix-BA. Sob a ótica das mediações sociais e mutações culturais (MARTíN-BARBERO, 2004, 2008, 2009a, 2009b), observamos, a partir dessa perspectiva, a hipótese da Estrutura de Sentimento (WILLIAMS, 1977), na identificação das diferentes temporalidades que configuram as produções e nos permitem perceber como elementos residuais, emergentes e dominantes operam simultaneamente na constituição das narrativas. Nesse sentido, as análises examinam de que modo as contradições que constituem o material audiovisual e os sujeitos produtores revelam movimentos do tempo transpassados por valores, sentidos e práticas hegemônicas, mas também alternativas e oposicionais, considerando:

É essa relação entre valores e sentidos dominantes, valores e sentidos alternativos e oposicionais que pode nos ajudar a compreender o processo contínuo de renovação, recriação, tensionamento, conflito, resistência que caracteriza a hegemonia e que nos possibilita pensar que, ao menos em tese, uma hegemonia pode ser modificada. (GOMES, 2011, p. 41).

Assim, a heterogeneidade de forças culturais que atravessam e conformam os textos elaborados pela Equipe Iskálifá manifesta-se em uma produção audiovisual que nos diz sobre ser jovem na periferia da periferia. Pensado por Martín-Barbero como o lugar onde a relação entre os receptores e os meios acontece, o campo das mediações nos ajuda a observar as instâncias simbólicas da construção do coletivo. Essas dimensões são atravessadas por elementos que articulam diferentes temporalidades, valores e sentidos, desde manipulações e interesses mercantis à transformação das sensibilidades, dos modos

1 Bhabha (1998) ao discutir a ideia de nação propõe que uma "temporalidade disjuntiva" emerge da disputa entre o pedagógico e o performativo, e que o sujeito do discurso cultural é formado a partir da ambivalência entre esses dois pólos. Defende que "Essa temporalidade disjuntiva da nação forneceria a referência de tempo apropriada para representar aqueles significados e práticas residuais e emergentes que Williams localiza nas margens da experiência contemporânea da sociedade" (BHABHA, 1998, p. 210). 
de construir imaginários e identidades e deve nos possibilitar a "continuar o esforço por desentranhar a cada dia mais complexa trama de mediações que a relação comunicação/ cultura/política articula" (MARTíN-BARBERO, 2008, p. 12).

\section{Mediações, meio e cotidianidade}

Esse olhar para a dinâmica estabelecida entre diversas temporalidades que constituem o nosso viver cotidiano está implicado no modo como Martín-Barbero chama atenção para o que elabora como base fundamental do seu trabalho: uma percepção da comunicação não como questão de meios, mas de mediações. Essas mediações, para o autor, estabelecem-se a partir de dois eixos: um sincrônico, que guia o olhar para questões de produção e consumo, e um eixo diacrônico, que observa o modo como as mediações que constituem um produto comunicacional são processadas no tempo. É exatamente no exame da configuração comunicativa do processo histórico que Martín-Barbero recorre às noções de residual, emergente e dominante, centrais à hipótese de estrutura de sentimento, elaborada por Raymond Williams (1979) para observar a coexistência de valores relativos a diversas temporalidades inscritas na experiência social. A defesa do autor de que é preciso superar uma visão instrumental que costuma ver a comunicação como questão de meios e compará-la "com esta outra visão, todavia ainda minoritária, que insere a comunicação nas práticas, nas transformações que afetam todas as dimensões da vida" (MARTíN-BARBERO, $2009 b$, p.159) é fundamental na construção recente do mapa das mutações. No novo diagrama Martín-Barbero nos instiga a pensar uma relação entre a comunicação, seus meios, e a vinculação profunda que estabelecem com a cotidianidade e a construção de nós mesmos enquanto sujeitos. Sair da visão instrumentalista significa, portanto, assumir não a prioridade dos meios, mas que "o comunicativo está se transformando em protagonista de uma maneira muito mais forte" (MARTíN-BARBERO, 2009b, p.152).

Entendemos que o processo de construção subjetiva das garotas e garotos produtores revela a trama conflitual do social (MARTIN-BARBERO, 2004, p. 73) cuja articulação se processa no tempo e faz parte das condições de existência do sujeito humano. Assim, a contradição - ou ambivalência - que constitui os sujeitos produtores e o material produzido revela-se um dos grandes achados do exercício analítico e se coloca a partir da identificação tanto de movimentos explícitos de crítica quanto de reiteração do "estado de coisas". As duas dimensões estão imbricadas, como demonstramos a seguir.

\section{De onde vêm?}

No momento de produção do material audiovisual aqui analisado (2015/2017), o coletivo Equipe Iskálifá contava com 10 estudantes do ensino médio na Escola Estadual Rômulo Galvão, com idades entre 15 e 18 anos, moradores do município de São Félix, 
no interior da Bahia, da localidade conhecida como "135", considerada periférica na dinâmica local. Banhada pelo rio Paraguaçu, São Félix é uma cidade de pequeno porte no Recôncavo Baiano, localizada a 110 km de Salvador, a capital do estado.

O surgimento do coletivo e da produção audiovisual foi vinculado inicialmente a uma demanda escolar, com o primeiro vídeo produzido para ser apresentado em sala de aula. Em seguida, outros materiais foram elaborados tanto para a escola quanto para colocar em pauta temas de interesse dos jovens. É possível perceber três momentos organizativos que as meninas e meninos identificam como "fases". O primeiro é o Jornal Iskálifá, quando as produções respondiam prioritariamente à escola e exercitavam um formato de telejornal como expressão mais ou menos regulada pelo que eles dizem ser o "jeito da escola" 2 . No momento seguinte, Equipe Iskálifá, ainda provocados pela escola, os jovens começam a produção de outros formatos como documentários e vídeos ficcionais. No terceiro momento Equipe Iskálifá "nova fase" - termo usado por eles - dialoga com as marcas dos audiovisuais e performances dos youtuberes. As produções foram disponibilizadas na plataforma YouTube, mas conta atualmente apenas com as produções da "nova fase" .

Curiosamente, ainda que recorram ao telejornal, cuja forma comunicacional é bastante regulada, o uso da linguagem audiovisual para a realização do trabalho é vista no ambiente escolar como algo "descolado" e fez o grupo, inicialmente composto apenas por meninos, atrair meninas, tomando a expressão naquele formato como um escape em relação ao saber tradicional e livresco. Este percurso criativo do grupo se destaca na apropriação de linguagens, na relação com territorialidades, temporalidades e na arquitetura de identidades que analisamos a seguir.

\section{Território e temporalidades}

A constituição da experiência juvenil a partir de uma narrativa audiovisual que opera sentidos globais, locais, hegemônicos, periféricos, atuais e antigos (essa última é uma expressão usada por eles) simultaneamente se destaca no material produzido pela equipe. É um esforço de constituir um pertencimento identitário para si a partir de movimento duplo de inserção numa dinâmica juvenil massiva e, ao mesmo tempo, em um processo localizado, particular. Assim, o território apresentado nos produtos analisados oscila entre uma globalidade - conectada com consumos contemporâneos que marcam a cultura juvenil - e as marcas do lugar específico, territorializado a partir das práticas ordinárias dos sujeitos jovens em bairros populares: jogar bola, brincar de gude, esconde-esconde, bater papo na porta de casa, etc. A territorialidade evidencia, desta forma, a fluidez

2 O material empírico aqui acionado é fruto do trabalho de campo da Alice Anchieta, vinculada ao Projeto de Pesquisa "Juventudes e Territórios Periféricos: práticas culturais-comunicacionais em Cachoeira e São Félix". A aluna contou com bolsa PIBIC/ FAPESB. A roda de conversa foi realizada em dezembro de 2015, com seis integrantes do grupo, ao ar livre, numa praça do Bairro 135, em São Félix. O material foi gravado em áudio.

3 Disponível em https://www.youtube.com/channel/UC435XmqnP5lvCL2GhNlkp-A/featured. Acesso em 15 de abril de 2018 . 
do deslocamento entre as experiências dos jovens de hoje e aquilo que "a molecada gostava de fazer", operando matrizes culturais de temporalidades distintas no uso do espaço.

A trilha sonora do vídeo "Brincadeiras Antigas" é um marco dessa construção ao aproximar o bairro 135 da condição de "periferia global" e apresentar seus jovens moradores como consumidores bricouler, que acionam trechos/fragmentos de diferentes origens para compor sua nova narrativa colocando em tensão e diálogo diferentes matrizes culturais e temporalidades e fazendo emergir na narrativa um sentido de diacronia. A trilha sonora, que funciona como áudio principal sobre a imagem na maior parte do tempo no vídeo, é composta pelo tema musical do filme Missão Impossível - um blockbuster estadunidense -, duas músicas do rapper brasileiro Emicida - Triunfo e Levanta e Anda - e ainda pela música Tropa de Elite - trilha do filme brasileiro homônimo. Na abertura do vídeo, feita em slow motion e composta com a trilha instrumental do filme de aventura, os jovens do Iskálifá são apresentados como heróis, aventureiros - assim como Tom Cruise - dispostos a realizar grandes feitos. A conexão global com as marcas do hegemônico é colocada em cena para representar seis jovens negros, de uma periferia do nordeste do Brasil, com a ressignificação da distância espaço-temporal entre as duas situações.

Na sequência, os raps de Emicida acionam uma territorialização da narrativa pela noção de periferia e pelo histórico das lutas travadas cotidianamente pelos sujeitos nesses territórios de exclusão, através de versos que reforçam a ligação com a rua e com as lutas. São textos como Na pista, pela vitória, pelo triunfo, A rua é nóis, é nois, é nóis (onde nóis, brigamos por nóis) ou Irmão, você não percebeu que você/ É o único representante do seu sonho na face da Terra? / Se isso não fizer você correr, chapa/ eu não sei o que vai. A edição parece sugerir que a "missão impossível" desses sujeitos é a de construir uma experiência de vida digna nesses territórios. As dificuldades dessa tarefa são costuradas ainda por uma teia de sentidos que emerge com o uso da música Tropa de Elite com um refrão que funciona de modo tão ambíguo quanto o filme e permite desde uma visão crítica à atuação da polícia militar e seu batalhão de operações especiais até uma certa glamourização da violência.

O vídeo mostra espaços que são relevantes para os jovens autores: suas casas compõem cenários bastante simples e locações adaptadas, o enquadramento do rio Paraguaçu não é aquele comum nos postais e fotos turísticas, e sim o trecho do rio que está perto, no cotidiano de cada um. Assim, "o 135" de São Félix é preenchido de sentidos, de sociabilidade, de cotidianidade a partir da sua situação periférica, cujos contornos, longe do apelo ao glamour da cultura pop da trilha sonora, remetem à condição econômica restrita que atravessa passado e presente.

Há também uma negociação com a memória coletiva e um deslizamento entre passado e presente, ao colocar em cena situações de brincadeiras de rua, identificadas como "antigas", enquanto o vídeo apresenta uma trilha sonora "de hoje", do tempo deles. Essa escolha musical que se relaciona com o presente indica a possibilidade de atualização 
dessa experiência, de modo a fazer parte da vida deles, no agora, como práticas que podem ser ressignificadas a cada uso, a cada partilha.

O grupo também recorre a certa ambiguidade relacionada à construção do sujeito praticante das brincadeiras que é apresentado como um "outro". A princípio, o distanciamento é essencialmente temporal, já que o próprio narrador afirma que isso "hoje não acontece mais". Mas esse distanciamento parece também ser uma tática de buscar para os jovens que narram um lugar de voz autorizada sobre o jovem do passado pela reprodução de marcas e práticas hegemônicas dos meios tradicionais de comunicação, ainda que inseridas em um exercício de se fazer visível e autor de uma voz com traços do contra-hegemônico, de que se contrapõem ao estado de coisas.

\section{Ser na ambiguidade}

A pluralidade de matrizes culturais acionadas no material produzido pela Equipe Iskálifá e a força da contradição constituidora desses sujeitos jovens de periferia podem ser observadas também no modo como eles se apropriam das convenções de linguagem. Essas matrizes retomam complexos entremeados de resíduos e inovação, anacronismos e modernidades que dialoga com estratégias de uma gramática discursiva partilhada entre recepção e produção (MARTíN-BARBERO, 2008). Assim, a primeira fase, marcada pela produção de vídeos que apresentam referências mais hegemônicas da linguagem do telejornal, é identificada como um momento em que a regulação ou o "jeito da escola" - é a característica mais atuante.

Nos primeiros vídeos pertencentes a essa fase apenas dois garotos aparecem no espaço da bancada de apresentação, vestidos com ternos - marca importante na construção de credibilidade dos jornalistas que apresentam jornais televisivos no país. Historicamente, a cena de apresentação instituída na bancada é tomada como condição estruturante do telejornal de rede brasileiro e forma de reconhecimento de suas marcas, lugar de construção da autoridade de uma fala supostamente especializada do jornalismo (GUTMANN, 2014, p. 118). Construído na relação com o território, com o rio Paraguaçu aparecendo ao fundo, este lugar de autoridade materializa uma condição de apropriação das formas na relação com os elementos de proximidade do cotidiano.

Em um vídeo da segunda fase de produção, identificado como Jornal 3, a convenção da bancada é tomada como uma referência mais flexível e permite que os jovens da equipe, que já conta com a presença de garotas, se apresentem em uma bancada ampliada. Ainda que os dois garotos que já compunham a bancada na edição anterior (Abrão Fernandes e Rodrigo Gonzaga) assumam um lugar de hierarquia como os sujeitos que efetivamente figurativizam a apresentação do jornal - o que lhes rende, inclusive, o papel daqueles que distribuem as falas e abrem espaço para uma maior pluralidade de vozes -, a presença de mais integrantes nesse espaço indica flexibilização das referências que compõem 
o produto audiovisual. É curioso observar que, embora nos telejornais mais convencionais haja, atualmente, um aumento da conversação entre apresentadores na bancada, a dinâmica representada pelos garotos assume um contexto comunicativo de conversação com piadas, que é uma marca presente, por exemplo, na estruturação da bancada do CQC (TV Bandeirantes) ${ }^{4}$ como uma das formas pelas quais o programa subvertia convenções do jornalismo televisivo brasileiro. Enquanto os dois jovens de paletó e gravata realizam uma performance mais convencional, os outros garotos vão tomando lugar no espaço com maior liberdade no modo como constroem sua expressão e estabelecem o diálogo entre si, acionando referências de outros modos de composição de linguagem de programas jornalísticos.

Em suas apresentações pessoais, são provocados a se localizar a partir daquilo que fazem "fora do Jornal Iskálifá, qual a sua profissão" e, curiosamente, ainda que saibamos que todos são ainda estudantes, passam a apresentar atividades que Ihes identificam pessoalmente como aquilo que eles fazem fora do jornal e, portanto, fora da escola. Assim, reivindicam um sentido de existência independente daquele espaço institucional através de um ser sujeito que dialoga com suas vidas cotidianas. É importante observar que, nesse sentido, o recurso a uma forma televisiva reconhecida como lugar de seriedade e credibilidade, que é o telejornal, parece sustentar o reconhecimento dos lugares de atuação reivindicados pelos garotos quando se assumem músicos, youtubers e, mesmo, desempregados. Esse deslocamento efetivado a partir de uma matriz televisiva hegemônica no passado, fortemente codificada, para a conciliação com formas audiovisuais mais fluidas e inventivas atua também no sentido de reforçar a afirmação de subjetividades dessas garotas e garotos de modo credível e autorizado.

Essa recorrência a formas convencionalmente reconhecidas da linguagem do telejornal dialoga com subversões possíveis tanto da forma, quando da expressão dos garotos e garotas da Iskálifá. Mas também no diálogo com a subversão dessas formas, revelam-se dinâmicas de reprodução de poder, como a atribuição de lugares hierarquizados para a mulher e para o homem. A participação das garotas nesse momento da bancada e em outros vídeos produzidos pela Equipe Iskalifá chama-nos atenção por exibir uma dinâmica entre disputa e controle. Essa tensão é configurada a partir do modo como elas são integradas à equipe e constituídas no vídeo através da linguagem do coletivo. É construída a oposição entre a figura feminina da "repórter Lai" e das duas outras garotas, a comentarista Emily e a repórter Enaire Rodrigues. Enquanto Lai entra tímida, um pouco calada, sem nunca olhar para a câmera diretamente, Emily e Enaire entram sorrindo, vestindo cores fortes, com posturas confiantes e falas diretas para o espectador. Constrói-se, então, uma oposição espacial entre Lai, de um lado, Enaire e Emily de outro na distribuição da bancada e no modo como o diálogo com os garotos se dá. A postura

4 Custe o que Custar (CQQ) - programa televisivo semanal exibido pela Rede Bandeirantes no período de 2008 e 2015. Para reflexão sobre o referido programa ver GUTMANN, SANTOS e GOMES. Eles estão a solta, mas nós estamos correndo atrás. Jornalismo e entretenimento no Custe o que Custar. E-Compos, Brasília, v.11/n.2, maio/ago 2008. 
de Emily e Enaire, ao contrário de ser tomada como algo que sustenta sua autonomia, é interpretada pelos garotos como algo que não é aceitável para garotas quando eles dizem que Lai "é a única normal" entre as três.

No mesmo vídeo, uma espécie de paródia do quadro de previsão do tempo apresentanos um escárnio machista e racista de Maju, em referência à jornalista do Jornal Nacional, representada por um garoto. Vestido de mulher, com seios falsos, maquiagem exagerada, peruca e uma tiara de antenas cor de rosa, o garoto fala da previsão de vento com folhas em uma região e flores da primavera em outra, enquanto folhas e flores são atiradas em direção a ele e ouvimos risadas de fundo. Quando os risos se intensificam, a câmera se movimenta para mostrar as garotas do grupo posicionadas em um degrau abaixo, fazendo a parte técnica de atirar coisas que simulam os fenômenos temporais. Embora haja outro garoto que segura o mapa, as garotas são mostradas como algo descolado, aquelas que riem e fazem graça. O escape que permite a subversão da forma tradicional de linguagem aparece aqui como modo de reforçar uma piada que recorre a lugares comuns de construção de uma subjetividade conservadora, relacionada à força da tradição de uma cultura patriarcal tradicional nos termos de Williams (1977).

No movimento de apelo que fazem às formas audiovisuais - ora marcado pela recorrência a uma matriz televisiva mais convencional, ora convocando marcas de ruptura à convenção reconhecida - o telejornal deixa de ser a referência principal enquanto forma para dar lugar aos reality shows, videoclipes, documentários, ficção e vídeo amador para citar alguns. São hibridizações de linguagens, organizadas em materialidades constituídas mais fortemente nas produções audiovisuais para a internet e YouTube, marcando uma passagem para o "jeito deles", diferente do "jeito da escola".

\section{Audiovisuais na luta popular}

Examinamos a linguagem utilizada nos audiovisuais da Equipe Iskálifá como mediação, ação e expressão, feita de signos e povoada de símbolos que abrigam o diálogo e as lutas, conectando a construção de subjetividades aos laços tecidos nas experiências sociais (MARTíN-BARBERO, 2014, p. 31). Em sua dimensão de ação, a linguagem é entendida como práxis que inscreve o sujeito na sociedade, como coesão e exclusão social. Emerge no discurso do contexto sócio-histórico e sob a regulação deste através de regras que configuram a situação comunicativa. Para Martín-Barbero (2014), pesquisar a linguagem como expressão é localizar sua potência primordial de dar existência à significação e perceber como é a experiência do falar para o sujeito que utiliza palavras e significados criados no passado para produzir uma palavra inédita, como é o caso do termo "Iskálifá", adotado pelos jovens 5 .

5 O nome e a grafia do termo que identifica a autoria das produções expressam o esforço criativo do grupo, numa ligação com o neologismo 'escalifar' que significa "utilizar algo de maneira excessiva" segundo o Dicionário de Baianês, editado em 1992 na Empresa Gráfica da Bahia, com expressões típicas da linguagem cotidiana do baiano. 
Aspectos relativos à identidade dos jovens emergem imbricados à experiência do passado de questões relativas à raça que se destacam em três vídeos da equipe, com o caráter contraditório próprio à luta cultural, e referem-se a um campo cujo debate transcende o alcance deste artigo, mas apontam para uma realidade aferida nas pesquisas no país. Segundo o Atlas da Violência (IPEA, 2017), sete em cada dez pessoas assassinadas no Brasil são negras. Na faixa de 15 a 29 anos, são cinco vidas perdidas para a violência a cada duas horas. De 2005 a 2015, enquanto a taxa de homicídios por 100 mil habitantes teve queda de $12 \%$ para os não-negros, entre os negros houve aumento de 18,2\%. Uma pessoa negra tem $23,5 \%$ mais chance de ser assassinada do que uma pessoa branca de qualquer faixa etária.

Nossas análises examinam os sentidos constituídos nas formas comunicacionais a partir do pensamento de Achille Mbembe (2014) de que a raça não existe como fato físico, antropológico ou genético, mas opera como criação fantasiosa, resultante de projeto ideológico que objetiva desviar a atenção de conflitos mais explícitos no passado, como as luta de classes ou de sexos. No vídeo de quase cinco minutos sobre Martin Luther King, é contraditório o apelo à superação inspirada na luta do líder pacifista, nos anos 60 do século passado, e uma construção autoral dos jovens que retorna à escravidão como vivência do presente. O minidocumentário inclui um clipe da música In the name of love, da banda U2, com legendas da letra em português, imagens do ativista e um jogral com falas dos estudantes sobre percepções acerca da noção de raça com metáforas religiosas. Apesar de repetir o olhar apaziguador das diferenças sobre a trajetória de Luther King, assassinado em 1968, hegemônico na mídia, o grupo enfatiza sofrimentos de "transformar a pessoa humana numa coisa, num objeto ou em mercadoria" (MBEMBE, 2014, p. 26). Os jovens atualizam elementos residuais da cultura brasileira com a presentificação de um passado ainda vivo e a repetição da espera por uma transformação, mas também evidenciam a anacronia entre o olhar sobre o presente e a experiência pretérita da sociedade escravocrata, atualizando o desencanto com o futuro de ontem que, na percepção dos jovens, não chegou. São frases como: 'eu tenho um sonho que um dia os filhos dos escravos e os filhos dos donos dos escravos sentarão juntos na mesa da fraternidade'; 'com esta fé, nós poderemos trabalharmos juntos, lutarmos juntos, rezarmos juntos, defender a liberdade juntos pra quem sabe um dia sermos livres'. No jogral, emerge a escrita da luta que conecta passado e presente através da expressão de sentimentos de um ser humano ainda escravizado.

\section{Audiovisuais - escola, televisão, YouTube}

Se nos materiais produzidos na relação com a escola nas duas primeiras fases da produção do grupo as matrizes midiáticas são mais diversificadas, nos seis vídeos postados no YouTube, em janeiro de 2016, a denominação Jornal dá lugar à Equipe 
Iskálifá, com a prevalência de vídeos com disputas juvenis e curiosidades, relativos à cultura dos desafios, marcante em canais voltados ao público jovem no YouTube. Essas produções tensionam a relação com marcações de tempo e espaço hegemônicas nos canais mais vistos do YouTube, em que não estão os corpos, cotidianidades e experiências de jovens negros relacionados a um território considerado periférico. A cidade e o ambiente doméstico aparecem como marcações do cotidiano e das socialidades das classes populares às quais os jovens pertencem, articulando valores e sentidos tradicionais hegemônicos a comunicabilidades atuais. O grupo mostra domínio das tecnicidades próprias de vlogueiros/ youtubers, como a exibição do endereço das redes sociais, gestos para marcar o diálogo com o espectador virtual, apelos para que se inscreva no canal, comente: 'se vocês gostaram desse vídeo, dá um like'.

O vídeo Acerte a música destaca-se ao combinar a matriz televisiva de programa de auditório com candidatos desafiados a identificar músicas a partir de dicas do apresentado ${ }^{\text {r6 }}$, com elementos de canais de desafios no YouTube cujas práticas remetem à sociabilidade juvenil de transformar a superação de obstáculos em diversão, interação e afirmação de uma forma de vida. O grupo aparece sentado ao lado de um laptop e a regra é renegociada para que não apenas os derrotados bebam uma mistura, mas todos, inclusive o câmera. Este é o momento em que os jovens mais se divertem, ao tomar o shake, com ingredientes como catchup, queijo, quibe, fermento, café, farinha, cebola, etc. Dispostos a marcar presença com seus corpos e experiências que dizem também de outros tempos e espaços não hegemônicos, eles dizem "YouTube é assim!", e desafiam aos mais reticentes: "vai arregar, é?". Todos cospem, mas se divertem, riem e se apropriam de tecnicidades para inscrever identificações próprias a experiências não hegemônicas na plataforma mundial.

\section{Considerações finais}

Observamos no material apresentado a relação entre linguagem audiovisual e experiências da cultura popular como embate cultural em operação, sob uma perspectiva marcada por relações temporais do pensamento histórico que exige "destacar a visão processual do mundo e pensar as práticas e processos comunicacionais como próprios de um dado momento e lugar" (RIBEIRO, LEAL \& GOMES, 2017, p. 41). A relação com a institucionalidade da escola, que marca metade das produções elaboradas em diálogo com gêneros midiáticos variados, ajuda-nos a perceber a contradição de um processo em que a formação acontece com os constrangimentos de controle e silenciamentos de uma cultura que a constitui a serviço do mercado de trabalho, mas que também tem na dimensão dialógica da comunicação, constituidora da cotidianidade dos sujeitos alunos, a abertura para batalhas culturais (MARTíN-BARBERO, 2014). O investimento desses jovens na apropriação das linguagens, a partir da relação tradicional com a escola e com formas

6 Qual é a Música era o nome de um quadro do programa Sílvio Santos, no SBT, desde os anos 70. 
culturais diversas, em especial as audiovisuais mais contemporâneas, é fundamental para que se produzam como sujeitos com um corpo e com o corpo um mundo, um tempo e um espaço próprios.

As apropriações que os sujeitos da Equipe Iskalifá fazem das formas e tecnologias audiovisuais e da pluralidade de matrizes culturais que constituem sua cotidianidade parecem indicar um movimento em que os vídeos produzidos por esses sujeitos jovens revelam-se como "um modo de inserção dos aprendizes no mundo da criatividade, da atividade profissional e da participação política" (MARTíN-BARBERO, 2014, p. 15). Esse movimento dialoga com a constituição daquilo que Jésus Martín-Barbero (2014) considera o âmbito de uma inteligência compreensiva ou expressiva que compreende a tecnologia não como algo apartado, usado apenas como instrumento, mas enquanto instância formadora de capacidades perceptivas.

Os jovens do Iskalifá partilham uma experiência de periferia que está assentada em diferentes matrizes e temporalidades que se organizam a partir de narrativas marcadas por ambiguidades. Esse movimento compartilha marcas culturais do território e da experiência temporal, mas também se constitui a partir de sua singularidade, funcionando como o mundo vivido, desorganizando compreensões dicotômicas da experiência e das resistências que acontecem "nos becos, nas vielas, nos morros", como eles afirmam ao final do vídeo Brincadeiras Antigas.

A escola pública, lugar em que o protagonismo é tomado por esses sujeitos aprendizes e produtores de um dizer sobre si mesmo, revela-se como palco para a apropriação contraditória de sentidos do vivido e das temporalidades que os atravessam. Nessa dinâmica, os elementos de subversão e de inovação frente à tradição que aparecem como um ponto forte na elaboração de formas televisivas dos vídeos iniciais, como a ampliação da bancada, são deixados de lado para emprego da linguagem com características da comunicabilidade própria de programas elaborados para a internet - como a exibição para a câmera que toma o espectador como testemunha do momento de diversão produzido no sentido de incitar uma partilha a ser materializada em likes e visualizações. As referências à cultura pop aparecem associadas a uma cultura juvenil dos desenhos animados, ainda que acionamentos de brincadeiras realizadas nas matrizes televisivas de programas de auditório também ganhem espaço. Esse mostrar-se a partir de formas audiovisuais é construído em um sentido que dialoga já não apenas com demandas escolares de uma crítica dos temas propostos, mas com um sentido contemporâneo de juventude conformado também nas competências hegemônicas mais atuais de domínio da expressão midiática, pela possibilidade de ocupar um espaço de difusão como o YouTube.

As análises indicam tensionamentos inscritos nas produções do grupo de jovens de São Félix em que contradição, tensão e ambiguidade são designações da espessura da luta em termos de incorporação, distorção, resistência, negociação e recuperação na cultura popular, tomada aqui como arena de disputa entre forças populares e hegemônicas, 
procedentes de experiências temporais distintas. A reflexão acerca de produções audiovisuais mostra o lugar da experiência social na relação com o território e a noção de juventude que se apropria da palavra, inscrevendo a cotidianidade familiar na relação com temporalidades e competências de gênero abertas e fluidas.

Daniela Abreu Matos é professora do Programa de PósGraduação em Comunicação- Mídia e Formatos Narrativos da Universidade Federal do Recôncavo da Bahia. É doutora em Comunicação pela Universidade Federal de Minas Gerais.

d.abreu.matos@gmail.com

Jussara Peixoto Maia é professora do Programa de PósGraduação em Comunicação - Mídia e Formatos Narrativos da Universidade Federal do Recôncavo da Bahia. É doutora em Comunicação e Cultura Contemporâneas pela UFBA.

jussaramaia@uol.com.br

Valéria Maria Vilas-Bôas é professora do Centro Unioversitário Jorge Amado. É doutora pelo Programa de Pós-Graduação em Comunicação e Cultura Contemporâneas da UFBA.

lelavbs@gmail.com

\section{Referências}

BHABHA, H. O local da cultura. Belo Horizonte: Editora da UFMG, 2001.

GOMES, I. Raymond Williams e a Hipótese Cultural da Estrutura de Sentimento. In: GOMES, Itania Maria Mota; JANOTTI, Jéder (Org.). Comunicação e Estudos Culturais. Salvador: Edufba, 2011.

GUTMANN, J. Formas do Telejornal: linguagem televisiva, jornalismo e mediações culturais. Salvador: EDUFBA, 2014.

Instituto Brasileiro de Geografia e Estatística. Censo Demográfico 2010. Rio de Janeiro: 2010. Disponível em https://biblioteca.ibge.gov.br/visualizacao/periodicos/94/cd_2010_religiao_deficiencia. pdf. Acesso em 25 jan 2019

Instituto de Pesquisa Econômica Aplicada. Atlas da Violência. Rio de Janeiro: 2017. Disponível em http://www.ipea.gov.br/atlasviolencia/arquivos/downloads/8891-1250-170602atlasdaviolencia2017. pdf. Acesso em 25 jan 2019

MARQUES, A. Prefácio In: MATOS, D. A. Escritas da cidade - Juventudes e resistências nas periferias de Salvador. Curitiba: Editora Appris, 2018. 
MARTÍN-BARBERO, J. Ofício de cartógrafo: Travessias latino-americanas da comunicação na cultura. Edições Loyola, 2004. 2008.

Dos Meios às mediações: Comunicação, cultura e hegemonia. Rio de Janeiro: Editora UFRJ,

. As formas mestiças da mídia. Pesquisa FAPESP Online, edição, v. 163, p. 10-15, 2009a.

. "Uma aventura epistemológica" entrevista de Maria Immacolata Vassallo de Lopes em Matrizes. São Paulo: USP-ECA, 2009b.

A comunicação na Educação. São Paulo: Editora Contexto, 2014.

MBEMBE, A. Crítica da razão negra. Tradução Maria Lança. Portugal: Antígona, 2014.

RANCIÈRE, J. Políticas da Escrita. Rio de Janeiro: Editora 34, 1995.

RIBEIRO, A P G; LEAL, B S \& GOMES, I. A historicidade dos processos comunicacionais: elementos para uma abordagem In: MUSSE, Christina F; VARGAS, Herom \& NICOLAU, Marcos (orgs.). Comunicação, mídias e temporalidades. Salvador: Edufba, 2017.

WILLIAMS, R. Marxism and literature. Oxford Paperbacks, 1977.

\section{ERRATA}

No artigo <Os tempos no Paraguaçu: juventude, mediações culturais e Youtube>, com número de DOI $<$ http://dx.doi.org/10.1590/1982-25542019441753>, publicado no periódico <Galaxia>, Especial 1 Comunicação e Historicidades, pp.61 a 73,

ONDE SE LIA: Valéria Maria Vilas Bôas

LEIA-SE: Valéria Maria Vilas-Bôas 